20 Berkman LF, Berkman CS, Kasl SV, Freeman DH, Leo L, Ostfeld AM, et al. Depressive symptoms in relation to physical health and functioning in the elderly. Am J Epidemiol 1986;124:372-88.

21 LaVange LM, Stearns SC, Lafata JE, Koch GG, Shah BV. Innovative strategies using SUDAAN for analysis of health surveys with complex samples. Stat Methods Med Res 1996;5:311-29.

22 Paffenbarger RS, Wing AL, Hyde RT. Physical activity as an index of heart attack risk in college alumni. Am J Epidemiol 1978;108:161-75.

23 Uchino BN, Cacioppo JT, Kiecolt-Glaser JK. The relationship between social support and physiological processes: a review with emphasis on underlying mechanisms and implications for health. Psychol Bull 1996;119:488-531.

24 Mendes de Leon CF, Seeman TE, Baker DI, Richardson ED, Tinetti ME Self-efficacy, physical decline, and change in functioning in communityliving elders: a prospective study. J Gerontol Soc Sci 1996;51:183-90S

25 Adelmann PK. Multiple roles and psychological well-being in a national sample of older adults. J Gerontol Soc Sci 1994;49:277-85S

26 Phillips DP, King EW. Death takes a holiday: mortality surrounding major social occasions. Lancet 1988;24:728-32.

27 Berkman LF, Syme SL. Social networks, host resistance, and mortality: a nine year follow-up study of Alameda County residents. Am J Epidemio 1979;2:186-204

28 Kaplan GA, Salonen JT, Cohen RD, Brand RJ, Syme SL, Puska P. Socia connections and mortality from all causes and from cardiovascular disease: prospective evidence from eastern Finland. Am I Epidemiol 1988; 128:370-80.

29 Bygren LO, Konlaan BB, Johansson S-E. Attendance at cultural events, reading books or periodicals, and making music or singing in a choir as determinants for survival: Swedish interview survey of living conditions. BMJ 1996;313:1577-80

30 Zimmer Z, Hickey T, Searle MS. Activity participation and well-being among older people with arthritis. Gerontologist 1995;35:463-71.

31 Crespo CJ, Keteyian SJ, Heath GW, Sempos CT Leisure-time physica activity among US adults. Results from the third national health and nutrition examination survey. Arch Intern Med 1996;156:93-8.

32 Teasdale TW, Christensen AL, Pinner EM. Psychosocial rehabilitation of cranial trauma and stroke patients. Brain Injury 1993;7:535-42.

33 Yates EF. The dynamics of aging and time: how physical action implies social action. In: Birren JE, Bengtson VL, eds. Emergent theories of aging. New York: Springer, 1988:90-117.

(Accepted 20 May 1999)

\title{
Perinatal mortality and morbidity among babies delivered in water: surveillance study and postal survey
}

\author{
Ruth E Gilbert, Pat A Tookey
}

\begin{abstract}
Aim To compare perinatal morbidity and mortality for babies delivered in water with rates for babies delivered conventionally (not in water).

Design Surveillance study (of all consultant paediatricians) and postal survey (of all NHS maternity units).

Setting British Isles (surveillance study); England and Wales (postal survey).

Subjects Babies born in the British Isles between April 1994 and March 1996 who died perinatally or were admitted for special care within 48 hours of birth after delivery in water or after labour in water followed by conventional delivery (surveillance study); babies delivered in water in England and Wales in the same period (postal survey).
\end{abstract}

Main outcome measures Number of deliveries in water in the British Isles that resulted in perinatal death or in admission to special care within 48 hours of birth; and proportions (of such deliveries) of all water births in England and Wales.

Results 4032 deliveries ( $0.6 \%$ of all deliveries) in England and Wales occurred in water. Perinatal mortality was $1.2 / 1000$ (95\% confidence interval 0.4 to 2.9 ) live births; $8.4 / 1000$ (5.8 to 11.8) live births were admitted for special care. No deaths were directly attributable to delivery in water, but 2 admissions were for water aspiration. UK reports of mortality and special care admission rates for babies of women considered to be at low risk of complications during delivery who delivered conventionally ranged from $0.8 / 1000(0.2$ to 4.2$)$ to $4.6 / 1000(0.1$ to 25$)$ live births and from 9.2 (1.1 to 33) to $64 / 1000$ (58 to 70) live births respectively. Compared with regional data for low risk, spontaneous, normal vaginal deliveries at term, the relative risk for perinatal mortality associated with delivery in water was $0.9(99 \%$ confidence interval 0.2 to 3.6).

Conclusions Perinatal mortality is not substantially higher among babies delivered in water than among those born to low risk women who delivered conventionally. The data are compatible with a small increase or decrease in perinatal mortality for babies delivered in water.

\section{Introduction}

In the 1980s few clinicians offered delivery in water. ${ }^{12}$ By 1993 all maternity units in England and Wales had managed labour or delivery in water and nearly half had installed birthing pools. ${ }^{3}$ Perceived advantages include women feeling relaxed ${ }^{4}$ and more autonomous than in conventional deliveries ${ }^{5}$-although a review of three randomised controlled trials ${ }^{467}$ of labour in water showed no clear beneficial or adverse effects on mother or baby. ${ }^{8}$

The main advantage claimed for delivery in water is a gentler experience for the baby. Reports of possible adverse effects-hypoxic ischaemic encephalopathy ${ }^{9}$ and one death attributed to labour taking place in warm water $^{10}$ and infection due to delivery in water ${ }^{11-13}$-raise theoretical causal links. Only one report of a baby who died with waterlogged lungs ${ }^{14}$ is clearly attributable to delivery in water. No studies, however, have yet compared maternal or paediatric outcomes in similar groups of women delivering in water and delivering conventionally (not in water).

We conducted national surveys of maternity units and paediatricians to determine the risks of death or admission for special care for babies delivered in water and identified clinical findings that might relate to the use of water. We compared these results with rates for women at low risk of complications during labour or delivery who delivered conventionally.

\section{Methods}

From April 1994 to April 1996 (25 months) all 1500 consultant paediatricians in the British Isles were surveyed each month by the British Paediatric Surveillance Unit ${ }^{15}$ and asked to report whether or not they
Department of Epidemiology and Public Health, Institute of Child Health, London WC1N 1EH Ruth E Gilbert, senior lecturer in clinical epidemiology Pat A Tookey, senior research fellow Correspondence to: Dr Gilbert r.gilbert@ich.ucl.ac.uk

BMJ 1999;319:483-7 
Table 1 Mortality among babies delivered to "low risk" women, according to present study and other studies

\begin{tabular}{|c|c|c|c|}
\hline \multirow[b]{2}{*}{ Study } & \multirow[b]{2}{*}{ Type of study } & \multicolumn{2}{|c|}{ Study population } \\
\hline & & $\begin{array}{l}\text { No of deaths/study } \\
\text { population }\end{array}$ & $\begin{array}{l}\text { Mortality per } 1000 \text { live births } \\
(95 \% \text { confidence interval) }\end{array}$ \\
\hline $\begin{array}{l}\text { NHS surveillance and postal survey England } \\
\text { and Wales, 1994-6 (present study) }\end{array}$ & All babies delivered in water & $5 / 4030$ & $1.2(0.4$ to 2.9$)$ \\
\hline Scotland, $1990^{18}$ & Stillbirths and neonatal deaths in normal primiparous women* & $29 / 10266$ & $2.8(1.9$ to 4.1$)$ \\
\hline $\begin{array}{l}\text { North West Thames, 1992-3 (unpublished } \\
\text { data) }\end{array}$ & $\begin{array}{l}\text { Stillbirths and first week deaths in standard primiparous } \\
\text { women with a spontaneous, normal vaginal delivery }\end{array}$ & $14 / 10307$ & $1.4(0.7$ to 2.3$)$ \\
\hline Northern region, $1981-94^{22}$ & Women booked and delivered at home; perinatal deaths & $3 / 1733$ & $1.7(0.4$ to 5.1$)$ \\
\hline North Staffordshire Maternity Hospital ${ }^{17}$ & Extremely low risk (4\% of 32424 deliveries); perinatal death & $1 / 1312$ & $0.8(0.2$ to 4.2$)$ \\
\hline GP managed home births ${ }^{23}$ & 1 stillbirth, no perinatal deaths & $1 / 217$ & $4.6(0.1$ to 25$)$ \\
\hline
\end{tabular}

*Based on a subsample ( $16.1 \%$ of all maternities) of normal primiparous women (defined as women with no previous registrable pregnancy, a singleton birth, labour not induced, aged 16-35, delivery after 36 completed weeks, no antenatal admission or admitted for 24 hours or less, and no breech presentation).

** Unpublished data for 15 maternity units in North West Thames in 1992 and 1993 (94 353 births) based on a subsample of standard primiparous women (defined as white women with no previous registrable pregnancy, aged 20-34 years, height over $1.55 \mathrm{~m}$, singleton delivery, cephalic presentation, $>37$ weeks' gestation, delivered in the same unit as booked, no medical complications of pregnancy). ${ }^{24}$ Any standard primiparous women (14 546) who did not have a spontaneous, normal vaginal delivery or had missing data about perinatal death or admission to special care were excluded, leaving a total of 10307 births ( $11 \%$ of the total) for analyses.

knew of any births that met the case definition of "perinatal death or admission for special care within 48 hours of birth following labour or delivery in water." We analysed births in the British Isles from April 1994 to March 1996.

Using standard questionnaires, clinicians responsible for the mother and her child provided data about the labour, delivery, use of water, the baby's condition, diagnoses, ventilator and treatment requirements, and reason for admission for special care or death.

We evaluated underreporting of deaths by comparing our findings with reports to the confidential inquiry into stillbirths and deaths in infancy, a mandatory, regional notification scheme. Regional coordinators were contacted to determine whether any deaths after delivery in water had occurred in addition to those reported to the investigators.

A postal questionnaire was sent to all NHS maternity units in England and Wales in 1995 and again in 1996 to determine the total number of deliveries in water during the study period. Methods are described elsewhere.$^{16}$ No non-NHS units or non-NHS midwives were included in the survey.

We analysed the data using EpiInfo version 6, and confidence limits are based on the Poisson distribution.

\section{Results}

\section{Survey of maternity units}

Of 219 maternity units surveyed, 217 responded (213 in 1995 and 184 in 1996). We used the numbers of deliveries in water in England and Wales reported for calendar years $1994(\mathrm{n}=1881)$ and $1995(\mathrm{n}=2093)$ and for January-March $1996(\mathrm{n}=528)$ to estimate the number for the period April 1994 to March 1996 $(\mathrm{n}=4032)$. This constituted $0.6 \%$ of all deliveries. In all, $9 \%(380 / 4032)$ of deliveries in water took place at home; $83 \%$ (3328) of deliveries in water took place in southern England, 16\% (633) in the northern English regions, and 2\% (71) in Wales. Reports for 3304 (82\%) deliveries were derived from written records; 502 (12\%) were based on good estimates; and the rest were based on rough estimates. On the basis of returns from units that responded to only one survey (assuming no unit closures or change in the number of deliveries), the denominator was underestimated by 219 .

\section{Survey of paediatricians}

Of 96 reports of perinatal death or admission for special care after delivery in water during the study period, 64 fulfilled the case definition; of these, 53 were reported through the British Paediatric Surveillance Unit and 11 directly to the study coordinator from one unit carrying out a large number of water births. The remaining 32 reports were duplicates, ${ }^{12}$ made in error, ${ }^{9}$ or concerned births that occurred outside the study period. ${ }^{11}$ No additional deaths were notified by the confidential inquiry into stillbirths and deaths in infancy. Thirty seven of the 64 reports involved delivery in water; in the other 27 , only the labour took place in water.

\section{Water conditions}

No information was given about water temperature for 26/64 births. In many instances the temperature was described as comfortable or not known. In 12 cases the recorded temperature was $\geq 38^{\circ} \mathrm{C}$ (maximum $41^{\circ} \mathrm{C}$ ). Women who delivered in water spent more time immersed (median 185 (range 45-510) minutes) than women who were in labour in water but who delivered conventionally (150 (15-610) minutes).

\section{Babies delivered in water}

The reported numbers of perinatal deaths or admissions for special care after delivery in water were 31 in southern England, 5 in northern England, 1 in Scotland, and none in Wales, Northern Ireland, or the Irish Republic. Of the 37 women, 35\% (13/37) delivered at home, $51 \%(19 / 37)$ were primiparous (this was their first registrable pregnancy), 3/37 had labour induced and 2/37 received pethidine.

\section{Perinatal mortality in babies delivered in water}

There were 5 perinatal deaths among the 4030 live births in water in England and Wales (perinatal mortality 1.2 per 1000 live births $(95 \%$ confidence interval 0.4 to 2.9) (table 1). Two babies were stillborn, one after a concealed pregnancy delivered unattended at home with no previous antenatal care. The other stillbirth was diagnosed before immersion. All three postpartum deaths were associated with abnormal pathological findings: one baby died aged 3 days with neonatal herpes infection; one died aged 30 minutes with an intracranial haemorrhage after precipitate deliv- 
ery; and the third, who died aged 8 hours, was found to have hypoplastic lungs at postmortem examination.

Risk of admission for special care in babies delivered in water

In all, 35 babies in the British Isles-of whom 32 survived and 3 later died-were admitted for special care within 48 hours of delivery in water (table 2). One was born in Scotland, leaving 34 babies out of 4030 delivered alive in water in England and Wales admitted for special care, a risk of 8.4 per 1000 live births (5.8 to 11.8) (table 3). Of the 32 survivors, 13 required respiratory support (ventilation or continuous positive airways pressure ${ }^{6}$ or head-box oxygen ${ }^{7}$ ). Fifteen of the survivors had lower respiratory tract problems, variously labelled as pneumonia, transient tachypnoea of the newborn, or "wet lung"; ; suspected aspiration"; meconium aspiration" ; water aspiration" ${ }^{1}$; and "freshwater drowning" (1, who had hyponatraemia)).

Hypoxic ischaemic encephalopathy grade 2 or 3 or perinatal asphyxia was reported in 5 surviving children $(2,2$, and 1 respectively), including the baby in whom freshwater drowning was diagnosed (rate 1.2 per 1000 live births $(0.4$ to 2.9$)$ ).

Evidence of infection was reported in 2 babies who survived with pneumonia: in 1, group D streptococci were isolated from the maternal high vaginal swab; in the other, group B streptococci were isolated from the baby's skin swabs.

In the 32 survivors, 15 had other diagnoses or reasons for admission. Five babies had a snapped umbilical cord (of whom 1 required a transfusion, 1 developed hypoxic ischaemic encephalopathy grade 2 , and 1 had a chromosomal abnormality). One further baby had a chromosomal abnormality; one developed hypoxic ischaemic encephalopathy grade 3 and had transposition of the great arteries; three had stridor; and one had shoulder dystocia. No clear reason or diagnosis was given for the remaining 4 babies.

\section{Outcomes in women who were in labour in water but delivered conventionally}

No mortality or morbidity rates can be derived for babies born to women who were in labour in water but delivered conventionally as the denominator is unknown. Six deaths were reported, including 3
Table 2 Clinical diagnosis or reason for admission to special care in babies delivered in water

\begin{tabular}{lcccccc} 
& \multicolumn{5}{c}{ Clinical problem* } & \\
\cline { 2 - 6 } & $\begin{array}{c}\text { Lower } \\
\text { respiratory } \\
\text { tract }\end{array}$ & Infection & $\begin{array}{c}\text { Hypoxic } \\
\text { ischaemic } \\
\text { encephalopathy } \\
\text { (grade 2 or 3) }\end{array}$ & Other & $\begin{array}{c}\text { Total No } \\
\text { of babies }\end{array}$ \\
\hline Perinatal death & & 1 & & 4 & 5 \\
\hline Admission: & 8 & 2 & 4 & 3 & $13 \dagger$ \\
\hline Respiratory support required & 7 & & 1 & 12 & $19 \ddagger$ \\
\hline Respiratory support not required & 15 & 3 & 5 & 19 & 37 \\
\hline Total & & & & &
\end{tabular}

*Based on principal diagnosis or reason for admission.

†Four babies were counted twice. Of 3 babies with lower respiratory tract problems, 1 also had group D streptococci infection, detected from a maternal high vaginal swab; 1 also had group B streptococci infection, detected from surface swabs; and a third (freshwater drowning) also had hypoxic ischaemic encephalopathy grade 2 . One baby admitted with hypoxic ischaemic encephalopathy grade 3 also had transposition of the great arteries.

$\ddagger$ One baby was counted twice. The baby admitted with hypoxic ischaemic encephalopathy grade 2 also had a snapped cord.

stillbirths (2 unexplained and 1 intrapartum asphyxia attributed to the umbilical cord wrapped 5 times around the neck); 2 deaths in the first week of life (one attributed to the sudden infant death syndrome and the other to hypoxic ischaemic encephalopathy grade 3 in a baby with necrotic cerebral lesions at postmortem examination suggestive of antepartum hypoxia), and one death at 28 days after hypoxic ischaemic encephalopathy grade 3 attributed to severe shoulder dystocia. The 6 women whose babies died left the water between 30 minutes and 6 hours before delivery.

\section{Discussion}

The risks of perinatal death or admission for special care in babies delivered in water are based on small numbers and have wide confidence intervals. Underreporting is also possible. No additional deaths were identified through the confidential inquiry into stillbirths and deaths in infancy, and it is unlikely that any were missed. Underestimation of the denominator for NHS units is likely, however, as such deliveries are unusual and may not be routinely recorded. The figure for perinatal mortality is therefore probably an upper estimate. In contrast, we could not verify the reported admissions for special care. Underreporting of such admissions is likely.

Table 3 Risk of postnatal admission for special care among babies delivered to "low risk" women, according to present study and other studies

\begin{tabular}{|c|c|c|c|}
\hline Study & Type of study & $\begin{array}{l}\text { No of babies needing } \\
\text { special care/study } \\
\text { population }\end{array}$ & $\begin{array}{l}\text { Risk of special care per } 1000 \text { live } \\
\text { births ( } 95 \% \text { confidence interval) }\end{array}$ \\
\hline $\begin{array}{l}\text { NHS surveillance and postal survey England } \\
\text { and Wales, 1994-6 (present study) }\end{array}$ & $\begin{array}{l}\text { All babies delivered in water; admission for special } \\
\text { care within } 48 \text { hours }\end{array}$ & $34 / 4030$ & $8.4(5.8$ to 11.8$)$ \\
\hline Scotland, $1990^{18}$ & $\begin{array}{l}\text { Normal primiparous women undergoing } \\
\text { non-instrumental deliveries (any admission to } \\
\text { special care) }{ }^{\star}\end{array}$ & $482 / 7524$ & 64 (58 to 70$)$ \\
\hline $\begin{array}{l}\text { North West Thames, 1992-3 (unpublished } \\
\text { data) }\end{array}$ & $\begin{array}{l}\text { Standard primiparous women with a spontaneous, } \\
\text { normal vaginal delivery (any admission to special } \\
\text { care baby unit) }\end{array}$ & $380 / 10307$ & 37 (33 to 41$)$ \\
\hline North Staffordshire Maternity Hospital ${ }^{17}$ & $\begin{array}{l}\text { Extremely low risk ( } 4 \% \text { of } 32424 \text { deliveries); any } \\
\text { admission to neonatal unit }\end{array}$ & $14 / 1312$ & 11 (5.8 to 18$)$ \\
\hline GP managed home births ${ }^{23}$ & Babies requiring specialist care & $2 / 217$ & 9.2 (1.1 to 33$)$ \\
\hline
\end{tabular}

*Based on a subsample ( $16.1 \%$ of all maternities) of normal primiparous women (defined as women with no previous registrable pregnancy, a singleton birth, labour not induced, aged 16-35, delivery after 36 completed weeks, no antenatal admission or admitted for 24 hours or less, and no breech presentation).

** Unpublished data for 15 maternity units in North West Thames in 1992 and 1993 (94 353 births) based on a subsample of standard primiparous women (defined as white women with no previous registrable pregnancy, aged 20-34 years, height over $1.55 \mathrm{~m}$, singleton delivery, cephalic presentation, $>37$ weeks' gestation, delivered in the same unit as booked, no medical complications of pregnancy). ${ }^{24}$ Any standard primiparous women (14 546) who did not have a spontaneous, normal vaginal delivery or had missing data about perinatal death or admission to special care were excluded, leaving a total of 10307 births (11\% of the total) for analyses. 
Comparison with conventional deliveries

Comparable "low risk" deliveries include women who book and deliver at home and those who have no adverse obstetric history and undergo spontaneous, normal vaginal, non-instrumental delivery. Published and unpublished rates for these groups are shown in tables 1 and 3. The perinatal mortality observed in our study was similar to the rates for $(a)$ home deliveries, $(b)$ the extremely low risk women who constituted $4 \%$ of hospital deliveries in North Staffordshire, ${ }^{17}$ and $(c)$ the low risk women whose deliveries constituted $11 \%$ of all deliveries in the North West Thames region (unpublished data). Rates were slightly higher for women who delivered in Scotland, but this group included women with obstetric problems who were admitted for 24 hours or less during pregnancy.

Compared with low risk women who delivered conventionally in the North West Thames region-the largest dataset limited to spontaneous, normal vaginal deliveries at term in low risk women-our data are not compatible with an increased perinatal mortality risk of greater than 3.6 (relative risk for delivery in water 0.9 (99\% confidence interval 0.2 to 3.6$)$ ). The data are compatible, however, with a small increase or decrease in perinatal mortality in babies delivered in water compared with babies not delivered in water.

Rates of admission for special care of babies born to low risk primiparous women (constituting 11-16\% of all deliveries in the North West Thames region and Scottish ${ }^{18}$ studies respectively (table 3 ), were significantly higher than for babies delivered in water. One explanation for the relatively low rate of admission for special care after delivery in water is the selectivity of this approach. Women with an adverse obstetric history or who develop problems during pregnancy or labour are not likely to deliver in water. The risk of perinatal mortality or morbidity in those who do deliver in water is therefore extremely low. Other explanations include underreporting of admissions after delivery in water or the limit to admissions within 48 hours of birth; differing thresholds for admission in Scotland or the North West Thames region overall, compared with units that offer delivery in water; and a genuine low risk of morbidity in babies delivered in water.

\section{Specific clinical problems}

No comparative data are available for the risk of lower respiratory tract problems in babies of low risk women who delivered conventionally. Two admissions for water aspiration, however, may have been attributable to delivery in water, and similar cases have been reported in the literature. ${ }^{14} 19$ In lambs, inhibitory mechanisms that prevent breathing until contact with cool air can be overridden by sustained hypoxia. ${ }^{20}$ In theory, therefore, some babies with unrecognised chronic hypoxia may gasp underwater.

The risk of hypoxic ischaemic encephalopathy grade 2 and 3 in term babies has been estimated to be about 2 per 1000 live births (95\% confidence interval 1.6 to 2.9$),{ }^{91}$ similar to the rate for deliveries in water (1.2 per 1000 live births ( 0.4 to 2.9$)$ ). As the antepartum and intrapartum events that cause hypoxic ischaemic encephalopathy are uncertain, the suggestion that immersion in warm water may limit heat loss, affect fetal thermoregulation and cerebral blood flow, and
- Data on adverse effects of delivery in water have been limited

- Perinatal mortality and risk of admission for special care is similar for babies delivered in water and for low risk deliveries that do not take place in water

- The risk of perinatal mortality for babies delivered in water is similar to the risk for babies born by normal vaginal delivery to women at low risk of adverse outcome

- Delivery in water may have caused water aspiration in two babies and contributed to snapped umbilical cord in five

increase oxygen requirements is theoretical. ${ }^{10}$ Maintaining water temperature at or below blood temperature, however, would seem advisable. The lack of information on water temperature in $40 \%$ of reported cases in our study indicates room for improvement.

Our findings neither support nor refute concerns based on case reports of pseudomonas infection ${ }^{11-13}$ that water increases the risk of transmission of gut organisms from mother to baby. Reporting of five cases of snapped umbilical cord was an unexpected finding, although we found no published data on the risk of this complication in conventional deliveries. We postulate that bringing babies immediately to the surface of the water results in rapid cord traction over a longer distance than would be the case for conventional deliveries. Increased awareness of this potential problem and lowering of the water level before delivery may avoid such traction.

Use of water during labour with conventional delivery is common practice but not always recorded, so no reliable denominator data are available. It would be surprising, however, to find an increased risk of death or admission for special care in these women as they spent less time in water than women who delivered in water.

\section{Conclusion}

What implications do our findings have for practice? The similarity in perinatal mortality and morbidity in low risk women suggests that delivery in water does not substantially increase adverse perinatal outcomes. Overall rates may, however, mask specific benefits and harms, such as water aspiration or snapped umbilical cord. Owing to the small numbers in all studies of low risk women, we could not determine whether the low mortality and morbidity in babies delivered in water could be further reduced by conventional delivery.

From the National Perinatal Epidemiology Unit, Oxford, Natalie Kenney undertook the postal survey of maternity units, Jo Garcia and Sally Marchant gave helpful comments on the study design and manuscript, Fiona Alderdice commented on the study design; heads of local midwifery services provided the data. We thank Anne Welch and other contributors to the North West Thames region's maternity database for data on low risk women and Joannie Wilkinson, who analysed the data. We also thank the British Paediatric Surveillance Unit (funded by Children Nationwide Medical Research Fund), the paediatricians who reported babies, the midwives and doctors who completed questionnaires, the coordinators of the confidential 
inquiry into stillbirths and deaths in infancy, and others who provided advice and information to the study.

Contributors: Both authors designed the study, analysed the data, and wrote the paper. PAT collected the data and REG is the guarantor.

Funding: Department of Health.

Competing interests: None declared.

1 Odent M. Birth underwater. Lancet 1983;ii:1476-7

2 Church L. Waterbirth: one birthing center's observations. J Nurse Midwifery 1989;34:165-70.

3 Alderdice F, Renfrew M, Marchant S, Ashurst H, Hughes P, Berridge G, et al. Labour and birth in water in England and Wales. BMJ 1995;310:837.

4 Cammu H, Clasen K, Van Wettere L, Derde M-P. "To bathe or not to bathe" during the first stage of labour. Acta Obstet Gynaecol Scand 1994;73:468-72

5 Page L, Kitzinger S. A midwifery perspective on the use of water in labour and birth. Matern Child Health 1995;Jan:22-6.

6 Schorn MN, McAllister JL, Blanco JD. Water immersion and the effect on labor. J Nurse Midwifery 1993;38:336-42.

7 Rush J, Burlock S, Lambert K, Loosley-Millman M, Hutchison B, Enkin $M$. The effects of whirlpools baths in labor: a randomized, controlled trial. Birth 1996;23:136-43.

8 Nikodem VC. Immersion in water during pregnancy, labour and birth In: Cochrane Collaboration. Cochrane Library. Issue 3. Oxford: Update Software, 1998.

9 Levene ML, Kornberg J, Williams THC. The incidence and severity of post-asphyxial encephalopathy in full term infants. Early Hum Dev 1985;11:21-6.

10 Rosevear SK, Marlow N, Stirrat GM. Birthing pools and the fetus. Lancet 1993;342:1048-9.

11 Rawal J, Shah A, Stirk F, Mehtar S. Water birth and infection in babies. BMJ 1994;309:511.
12 Parker PC, Boles RG. Pseudomonas otitis media and bacteremia following a water birth. Pediatrics 1997;99:653.

13 Roome APCH, Spencer RC. Birthing pools and infection control. Lancet 1996;348:274.

14 Rosser J. Is water birth safe? The facts behind the controversy. MIDIRS Midwifery Digest 1994:4:4-6.

15 Hall S, Nicoll A. The British Paediatric Surveillance Unit-a pioneering method for investigating the less common disorders of childhood. Report of a seminar held in June 1995. Child Care Health Dev 1997;24:129-43.

16 Alderdice F, Renfrew M, Marchant M, Ashurst H, Hughes P, Berridge G, et al. Labour and delivery in water in England and Wales: survey report. BrJ Midwifery 1995;3:375-82.

17 Arya R, Pethen T, Johanson R, Spencer S. Outcome in low risk pregnancies. Arch Dis Child 1996;75:F97-102.

18 Middle C, MacFarlane A. Labour and delivery of "normal" primiparous women: analysis of routinely collected data. $\mathrm{Br} J$ Obstet Gynaecol 1995; 102:970-7.

19 Barry CN. Could saline in the pool reduce the potential hazards? BMJ 1995;310:1602.

20 Johnson P. Birth under water-to breathe or not to breathe. Br J Obstet Gynaecol 1996;103:202-8.

21 Hull J, Dodd KL. Falling incidence of hypoxic-ischaemic encephalopathy in term infants. Br J Obstet Gynaecol 1992;99:386-91.

22 Northern Region Perinatal Mortality Survey Coordinating Group Collaborative survey of perinatal loss in planned and unplanned home births. BMJ 1996;313:1306-9.

23 Ford C, Iliffe S, Franklin O. Outcome of planned home births in an inner city practice. BMJ 1991;303:1517-9.

24 Cleary R, Beard R, Chapple J, Coles J, Griffin M, Joffe M, et al. The standard primipara as a basis for inter-unit comparisons of maternity care. $\mathrm{Br}$ J Obstet Gynaecol 1996;103: 223-9.

(Accepted 25 May 1999)

\title{
Polymorphism in high density lipoprotein paraoxonase gene and risk of acute myocardial infarction in men: prospective nested case-control study
}

\author{
Jukka T Salonen, Riikka Malin, Tomi-Pekka Tuomainen, Kristiina Nyyssönen, Timo A Lakka, \\ Terho Lehtimäki
}

Increased lipid peroxidation is associated with accelerated progression of atherosclerosis. ${ }^{1}$ Paraoxonase (paraoxonase/arylesterase) is an antioxidative enzyme in high density lipoproteins, which protect against coronary disease. ${ }^{23}$ It eliminates organophosphorus pesticides but also the products of lipid peroxidation. ${ }^{24}$ The mutation at position 54 of the paraoxonase gene in which methionine is substituted by leucine (Met54Leu) has an effect on paraoxonase, increasing its activity; people who have the methionine allele show decreased paraoxonase activity. ${ }^{4}$ Only a few studies have looked at the association of the Met54Leu polymorphism with coronary disease, ${ }^{25}$ and the findings are inconclusive. Thus we carried out a prospective study of the role of this polymorphism on the risk of acute myocardial infarction in healthy men from eastern Finland.

\section{Participants, methods, and results}

Our prospective nested case-control study was carried out among participants in the Kuopio ischaemic heart disease risk factor study. We examined 2682 (83\%) of 3235 invited men aged 42, 48, 54, or 60 during 1984-9. Blood samples were collected and risk factors assessed at baseline. A DNA sample was available for this study for 1137 men who were free of coronary disease. We registered and verified all myocardial infarctions- definite or possible-between the baseline examinations and the end of 1995 . $^{3}$ The mean follow up time was 8.5 years, and in patients who had had multiple infarctions we considered only the first.

The cases were all 55 men (among the 1137) who had had an infarction by 1995 . The controls were drawn from the remaining members of the same cohort. Two controls for each case (110 men) were matched according to the most important non-genetic risk factors for myocardial infarction in the Kuopio ischaemic heart disease risk factor study cohort. For the 165 men, paraoxonase genotypes were determined by using a polymerase chain reaction method with Hsp92II enzyme digestion. ${ }^{4}$ We used logistic regression modelling to analyse the association of paraoxonase genotypes with the risk of myocardial infarction.

Of the cases, 13 (24\%) were homozygous for the M allele (MM), 22 (40\%) were heterozygous (ML), and 20 $(36 \%)$ did not carry it (LL). Of the controls, $11(10 \%)$ had an MM genotype, 54 (49\%) an ML, and 45 (41\%) an LL. In a logistic model adjusted for the other strongest risk factors the odds ratio for the MM genotype was 3.38 (95\% confidence interval 1.17 to 9.83 ; $\mathrm{P}=0.025$ ) (table, model 1). An additional adjustment for serum concentration of the second subfraction of high density lipoprotein cholesterol $\left(\mathrm{HDL}_{2}\right)$ attenuated
Research Institute of Public Health and Department of Public Health and General Practice, University of Kuopio, PO Box 1627,70211 Kuopio, Kuopio, Finland

Jukka T Salonen professor of epidemiology Tomi-Pekka Tuomainen research fellow Kristiina Nyyssönen clinical biochemist Timo A Lakka senior research fellow continued over

BMJ 1999;319:487-9 